\title{
The impact of the interfaces of the driving automation system on a driver with regard to road traffic safety
}

\author{
Paula Razin ${ }^{1,}$, Arkadiusz Matysiak ${ }^{1}$, Mikołaj Kruszewski ${ }^{1}$, and Michat Niezgoda ${ }^{1}$ \\ ${ }^{1}$ Motor Transport Institute, Warsaw, Poland
}

\begin{abstract}
The article presents the results of the road safety-targeted research on the influence of driving automation system interfaces, regarding the highway chauffeur scenario. The verification of multisensory test stand operation was planned through the research targeting transfer of control in a driving simulator. Such examination on one hand allowed to verify its efficiency as a whole (as well as its modules), while on the other hand it helped to answer a significant question regarding the efficient and time-minimizing communication form with driver through the HMI. One of the main analyzed, road safety-targeted parameters was time needed for taking over the control of the vehicle. The results of conducted experiment show that providing the RtI information using all interfaces available in the vehicle may not to be the most effective way. The examinees achieved the best results when informed through visual and auditory interfaces $(t=3,84 \mathrm{~s})$. The next stage of the research will cover the analysis of the maneuvers made after the control takeover.
\end{abstract}

\section{Introduction}

In recent years, there has been a very dynamic development of advanced driving assistance and driving automation systems. This was influenced not only by ever newer manufacturers' proposals regarding technological solutions, but also by the decrease in component production costs, sensor systems and microprocessor technology. Novel solutions allow to obtain and process the data coming from the vehicle sensors and to perform adequate reactions. More and more frequently, such action results not only in warning the driver, but also in an autonomous performance of a driving maneuver, e.g. braking.

It is anticipated that over the next dozen years, the development of the automotive industry will be directed towards the pursuit for full vehicle automation (fully autonomous driving, 5th level of automation according to SAE) [1]. However, before it happens, the drivers will still have to perform some driving manoeuvres. Therefore, the human role will be important in controlling an automated vehicle (L2-L4 levels according to SAE). It will be necessary for the driver to adapt to new operating conditions and learn appropriate responses to eventual system errors or unforeseen dangerous situations in traffic, which

\footnotetext{
* Corresponding author: paula.razin@,its.waw.pl
} 
would force his intervention [2]. It will also be necessary to educate autonomous vehicle drivers both regarding the capabilities and limitations deriving from the functional characteristics of these vehicles [3].

\section{Research experiment}

The driver is informed about current road situation, possible threats and the necessity to take over the control through dedicated human-machine interfaces [4]. The reception of warning signals may occur in auditory, visual or haptic (vibrations) way.

The research was carried out in simulated conditions. The research scenarios required the drivers to take over the control during selected road situations. Such research on one hand enabled the verification of the efficiency of multisensoric stand's operation. On the other hand, it helped to answer a significant research question regarding the efficient way of communicating with a driver through the use of HMI interface, in order to minimize the time of taking over the control of the vehicle.

\subsection{Research stand}

\subsubsection{Passenger car simulator}

The experiment was carried out using high-class passenger car simulator AS1200-6. It is equipped in a full-scale, fully functional Opel Astra IV cabin. The simulator operates in 6 degrees of freedom, thank to Moog 6DOF2000E motion platform. The platform allows to perform cabin movements imitating a real-life drive [5].

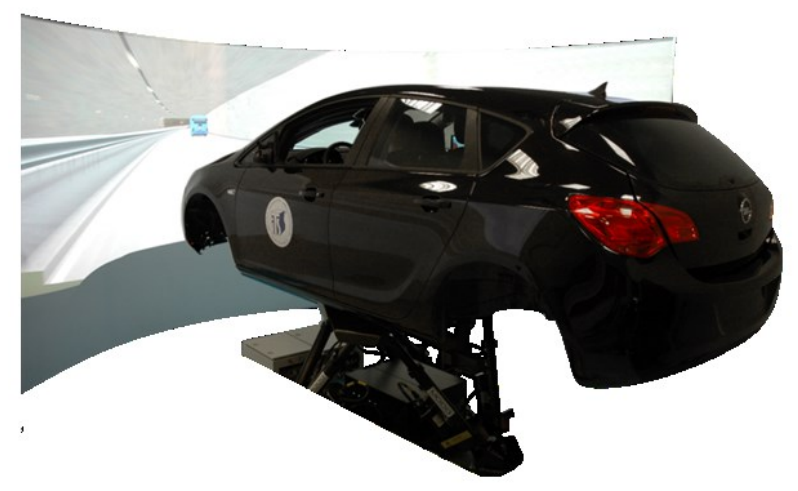

Fig. 1. High-class passenger car simulator AS1200-6.

Simulator's vision system consists of a cylindrical screen which covers ca. $200^{\circ}$ of driver's horizontal view and ca. $30^{\circ}$ of the vertical view. The cabin is additionally equipped with a microphone and CCTV, enabling the driver behavior monitoring and voice communication.

\subsubsection{Multisensory test stand}

Experiment was assumed to be conducted using a newly-built multisensory stand for HMI evaluation. Its construction covered adding several interfaces - touchscreens, vibration 
generators inside a driver seat and a dedicated sound system. The aim was to enable driverdedicated feedback using different sensory modalities of the interacting stimuli.

The multisensory stand consists of the following modules:

- visual - this module generates visual information in for the sake of driver-HMI interaction analysis. It consists of a simulator-integrated LCD dashboard enabling not only to show standard vehicle status data, but as well visual information on automation mode.

- auditory - audio module enables to generate auditory information for the examinees simultaneously with the events in the driving scenario.

- haptic - haptic module enables the generation of vibration stimuli in the driver's seat and synchronization of the haptic information with the simulation scenarios.

- ADS console - vehicle automation system management enables to switch on/off the system, adjustments of automated mode settings (e.g. velocity) and the display of current system status.

- integrative - synchronization-dedicated software which integrates all its elements as well as collects the asynchronous data, such as the events and their presentation.

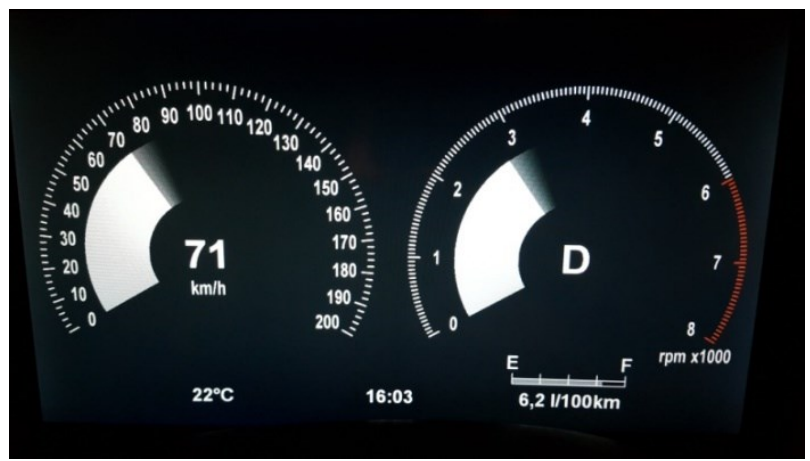

Fig. 2. Visual module of the HMI stand.

The dedicated screen which substituted the standard dashboard in the driving simulator presented i.e. warning lights, animated speedometer and odometer, clock, temperature. Additionally, the elements displayed asynchronously were also designed. The graphics signalizing the necessity to take over or give back the control, automation system status indications and cruise control settings.
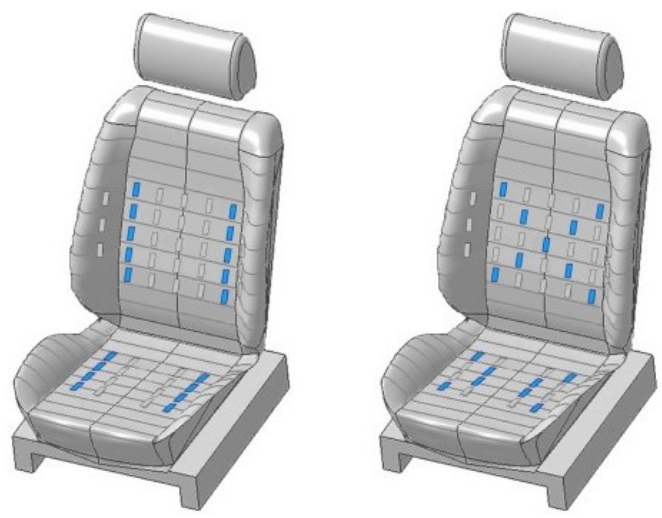

Fig. 3. The visualization of the seat used in HMI research by Stuttgart University. 
The vibration seat was designed to enable transferring the vibration signals to the driver. The solution used by Stuttgart University research served as a model [6].

The auditory signalizing capabilities were used through a built-in simulation engine system and enabled to give commands directly in the scenario. Information sounds of vehicle take-over system were specifically chosen, while their audibility was verified in different simulation-based road conditions, including traffic level, vehicle velocity and engine's rotation speed.

\subsection{Research group}

The research was conducted on a group of 30 adults who were a representative sample of B category drivers in Poland. The main requirements to access the research was the driving license possession for at least two years and active driving on a daily basis. The drivers represented three age groups, each consisting of 10 individuals. The first group were young drivers (20-25 years old), middle-aged drivers (30-40 yo) and the elderly drivers $(55+)$. Mean driver age was 38 years old $(\mathrm{SD}=14,04)$. The youngest driver was aged 20 , while the oldest one 64 .

\subsection{The course of the experiment}

The actual simulator-based research was preceded with an adaptive scenario. This scenario allowed the examinee to get acquainted with the steering mechanism, in order to behave in a natural manner during the research. Additionally, the driver became introduced with the control take-over system enabling to both act on driver's and vehicle's request.

The scenario lasted continously for over a dozen minutes. It was interrupted in case the examinee signaled severe simulation sickness symptoms. After driving the adaptation scenario the drivers filled the Simulation Sickness Questionnaire [7]. Examinees identified as simulation-sick were excluded from the further research stage and their results were not analyzed. In fact, only one participant withdrew from the examination due to aforementioned reasons.

Three potentially dangerous situations, requiring to perform TOR (Take-Over Request) were located on the test route: two road accidents and road works covering the rebuilding of the infrastructure and taking a detour.

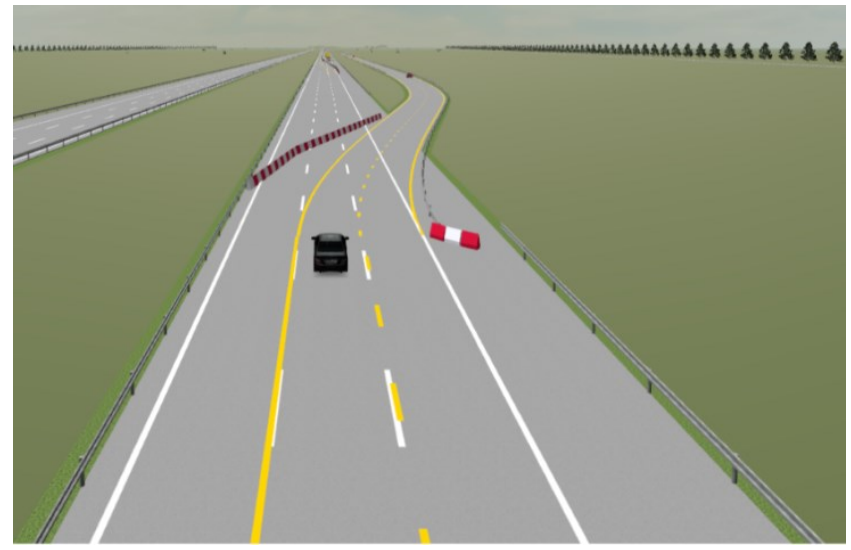

Fig. 4. Visualization of one of the TOR driving situations. 
Each of these situations were preceded with a one from a total of 3 designed HMIs, that are listed below:

- Visual information (displayed as a pictogram on a dashboard screen).

- Visual and auditory information (the same visual information provided together with an audio message).

- Visual, auditory and haptic information (message enriched with the pulsatory seat vibrations).

\section{The results}

The verification of multisensory stand operation was planned to be made by conducting the research targeting transfer of control in a vehicle with automated highway chaffeur functionality. The research on one hand allowed to verify the efficiency of multisensory stand and each of its modules, while on the other hand helped to answer significant research questions regarding the efficient ways of HMI-based communication with the driver. Its main aim was to examine which of them lead to time minimization of take-over activity. The main examined variable was time passed from the message transferred through different combinations of 3 stimuli (visual; auditory and visual; visual, auditory and haptic) to the moment of driver intervention (pushing gas pedal, brake pedal or steering wheel turn). RtI (Request to Intervene) timestamp was generated when the message about the necessity to take over the request was displayed to the driver. In this sense, it is a critical element for the analysis. It is considered as the beginning of the take-over process and from this moment on, the time needed for taking over the control is counted by the vehicle manufacturers.

Time to take over the control was taken into the analysis. Mean reaction time was calculated for all three road situations: $9,46 \mathrm{~s}(\mathrm{SD}=5,47)$ for visual stimuli, 5,64 $\mathrm{s}(\mathrm{SD}=$ $3,18)$ for visual, auditory and haptic stimuli and $3,84 \mathrm{~s}(\mathrm{SD}=1,40)$ for visual and auditory stimuli.

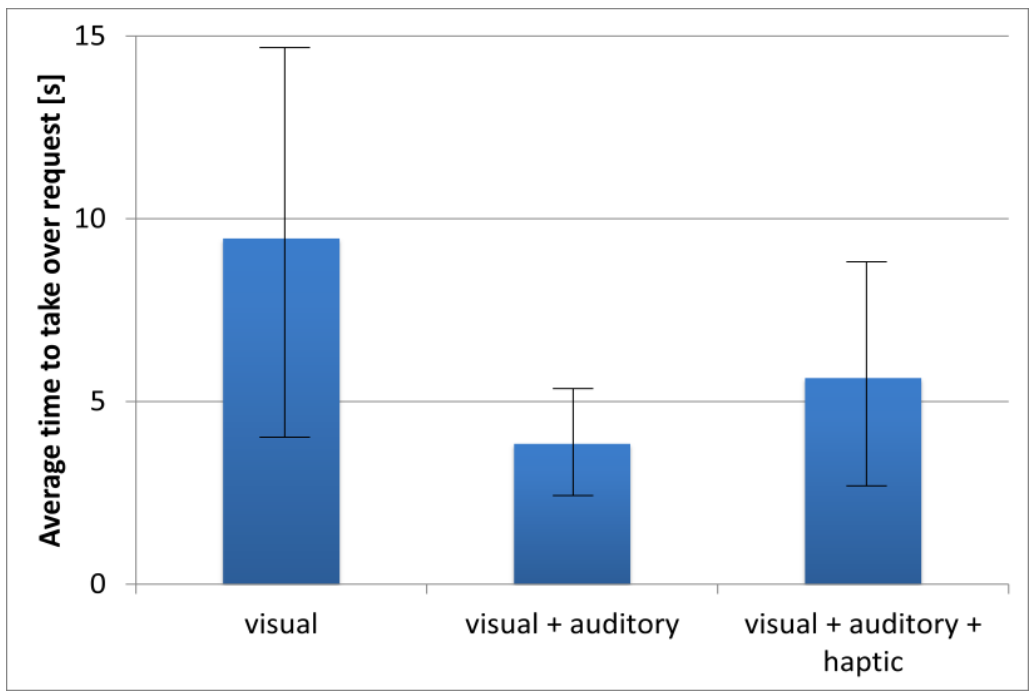

Fig. 5. Results of TOR time due to type of interface. 


\section{Conclusion}

The driver is informed about current road situation, possible threats and the necessity to take over the control through dedicated human-machine interfaces. The reception of warning signals may occur in auditory, visual or haptic (vibrations) way. The messages can be displayed on the screens at the control panel as well as next to standard indicators, e.g. speedometer and odometer. The best method to transfer the information to the driver is considered to be the one, that results in a quick, proper and intuitive reaction. It should not include the complex information processing process.

The conducted experiment results shows that providing the RtI information using all interfaces available in the vehicle may not to be the most effective way. Results shows that visual-auditory-haptic interface was less effective than visual-auditory interface. Nevertheless it was much more effective than visual interface. While participants were not forced to pay their attention on anything but driving majority of them were aware of the traffic conditions when RtI has been turned on.

The next stage of the research will cover the analysis of the maneuvers made after the control takeover. The parameters strictly connected with the vehicle movement will be analyzed, including change in velocity, steering wheel movements and vehicle lane position.

aDrive system was financed and supported by the project aDrive - PBS3/B6/28/2015, funded within Applied Research Program of the Polish National Centre for Research and Development.

\section{References}

1. SAE International, Surface vehicle recommended practice, J3016, Taxonomy and Definitions for Terms Related to Driving Automation Systems for On-Road Motor Vehicles (2016)

2. V.A. Banks, N.A. Stanton, Keep the driver in control: Automating automobiles of the future, Appl. Ergon. 53 pp. 389-395 (2016). doi:10.1016/J.APERGO.2015.06.020

3. M. Blanco, J. Atwood, H.M. Vasquez, T.E. Trimble, V.L. Fitchett, J. Radlbeck, J.F. Morgan, Human Factors Evaluation of Level 2 and Level 3 Automated Driving Concepts. Report No. DOT HS 812182 (National Highway Traffic Safety Administration, Washington DC, 2015)

4. W. Choromański, I. Grabarek, A. Spirzewska, Systemy Human Machine Interface (HMI) dedykowane samochodom poziomów L2/L3, Pr. Nauk. Politech. Warsz. Transp. 115 pp. 35-45 (2017)

5. M. Kruszewski, P. Razin, M. Niezgoda, M. Nader, Model oceny dodatkowego obciążenia poznawczego u kierowcy na podstawie badań $\mathrm{z}$ wykorzystaniem symulatora jazdy, Pr. Nauk. Politech. Warsz. - Transp. 118 pp. 155-166 (2017)

6. M. Schwalk, N. Kalogerakis, T. Maier, Driver Support by a Vibrotactile Seat Matrix Recognition, Adequacy and Workload of Tactile Patterns in Take-over Scenarios During Automated Driving, Procedia Manuf. 3 pp. 2466-2473 (2015). doi:10.1016/J.PROMFG.2015.07.507

7. M. Kruszewski, P. Razin, M. Niezgoda, E. Smoczyńska, T. Kamiński, Analiza efektów oddziaływania symulatora na powstawanie choroby symulatorowej w badaniach kierowców, Syst. Logistyczne Wojsk. 44 pp. 188-201 (2016) 